\title{
Proficient use of low spatial frequencies facilitates face memory but shows protracted maturation throughout adolescence
}

Citation for published version (APA):

Peters, J. C., \& Kemner, C. (2017). Proficient use of low spatial frequencies facilitates face memory but shows protracted maturation throughout adolescence. Acta Psychologica, 179, 61-67. https://doi.org/10.1016/j.actpsy.2017.07.004

Document status and date:

Published: 01/09/2017

DOI:

10.1016/j.actpsy.2017.07.004

Document Version:

Publisher's PDF, also known as Version of record

Document license:

Taverne

Please check the document version of this publication:

- A submitted manuscript is the version of the article upon submission and before peer-review. There can be important differences between the submitted version and the official published version of record.

People interested in the research are advised to contact the author for the final version of the publication, or visit the DOI to the publisher's website.

- The final author version and the galley proof are versions of the publication after peer review.

- The final published version features the final layout of the paper including the volume, issue and page numbers.

Link to publication

\footnotetext{
General rights rights.

- You may freely distribute the URL identifying the publication in the public portal. please follow below link for the End User Agreement:

www.umlib.nl/taverne-license

Take down policy

If you believe that this document breaches copyright please contact us at:

repository@maastrichtuniversity.nl

providing details and we will investigate your claim.
}

Copyright and moral rights for the publications made accessible in the public portal are retained by the authors and/or other copyright owners and it is a condition of accessing publications that users recognise and abide by the legal requirements associated with these

- Users may download and print one copy of any publication from the public portal for the purpose of private study or research.

- You may not further distribute the material or use it for any profit-making activity or commercial gain

If the publication is distributed under the terms of Article $25 \mathrm{fa}$ of the Dutch Copyright Act, indicated by the "Taverne" license above, 


\title{
Proficient use of low spatial frequencies facilitates face memory but shows protracted maturation throughout adolescence
}

\author{
Judith C. Peters ${ }^{\mathrm{a}, \mathrm{b}, *}$, Chantal Kemner ${ }^{\mathrm{c}, \mathrm{d}, \mathrm{e}}$ \\ a Department of Cognitive Neuroscience, Faculty of Psychology and Neuroscience, Maastricht University, Maastricht, The Netherlands \\ b Department of Neuroimaging and Neuromodeling, Netherlands Institute for Neuroscience, an institute of the Royal Netherlands Academy of Arts and Sciences (KNAW), \\ Amsterdam, The Netherlands \\ c Department of Developmental Psychology, Utrecht University, Utrecht, The Netherlands \\ d Department of Experimental Psychology, Helmholtz Institute, Utrecht University, Utrecht, The Netherlands \\ e Brain Center Rudolf Magnus, University Medical Centre Utrecht, Utrecht, The Netherlands
}

\section{A R T I C L E I N F O}

\section{Keywords:}

Face recognition

Face memory

Perception

Spatial frequency

Adolescence

\begin{abstract}
A B S T R A C T
Face perception is characterized by configural processing, which depends on visual information in the low spatial frequency (LSF) ranges. However, it is unclear whether LSF content is equally important for face memory. The present study investigated how face information in the low and high SF range plays a role in the configural encoding of faces for short-term and long-term recall. Moreover, we examined how SF-dependent face memorization develops in female adolescence, by comparing children (9-10-year-olds), adolescents (12-13-year-olds and 15-16-year-olds), and young adults (21-32-year-olds). Results show that similar to face perception, delayed face recognition was consistently facilitated by LSF content. However, only adults were able to adequately employ configural LSF cues for short-term recall, analogous to the slow maturation of LSF-driven configural face perception reported by previous studies. Moreover, the insensitivity to face inversion of early adolescents revealed their inadequate use of configural face cues regardless of SF availability, corroborating previous reports on an adolescent "dip" in face recognition. Like face perception, face recognition has a protracted maturational course. In (female) adolescence, sensitivity to configural LSF cues is developed, which aids not only configural face perception but also face memorization.
\end{abstract}

\section{Introduction}

Faces are perceived as an integrated configuration ('Gestalt') rather than as a collection of independent features (e.g., Sergent, 1984). This configural processing style appears to be a specific strategy for faces: When configural processing is disrupted, for example by presenting stimuli upside down, perception of faces is much stronger degraded than perception of other object classes (the so-called 'Face Inversion Effect' or FIE; Yin, 1969; see Rossion, 2008 for review). Importantly, configural information is mainly extracted from coarse information in the low spatial frequency (LSF) range (e.g., Bar, 2004; Goffaux, Hault, Michel, Vuong, \& Rossion, 2005; Sergent, 1986). In contrast, high spatial frequencies (HSF) convey information about local perceptual details, which enables the fine-grained processing of face features (Goffaux \& Rossion, 2006). Whereas research suggest the importance of LSF over HSF information for configural face perception (face discrimination), the role of SF in face recognition (face memory) has not been investigated yet. The present study investigates how face information in the LSF and HSF range play a role in the encoding of faces for short-term and long-term recall.

In typical adult face perception, information carried by low, mid, and high SF bands is combined according to a coarse-to-fine sequence (Goffaux et al., 2011; see Ruiz-Soler \& Beltran, 2006 for review). First, the rapidly available coarse LSF content is analyzed for configural cues. These cues are particularly important for the fast interpretation of holistic information emerging from the simultaneous processing of features, for example to establish emotional states (Vlamings, Goffaux, \& Kemner, 2009). Subsequently, more fine-grained information in HSF ranges is examined for featural aspects, for example to assess facial age (see Fig. 1 for examples of faces in which only LSF or HSF information is available). Previous psychophysical findings support this differential influence of information conveyed by low versus high SF ranges: Goffaux et al. (2005) showed participants displays with lowpass or high-pass filtered face triplets for which they had to indicate

\footnotetext{
* Corresponding author at: Department of Cognitive Neuroscience, Faculty of Psychology and Neuroscience, Maastricht University, P.O. box 616, 6200 MD Maastricht, The Netherlands.

E-mail address: j.peters@maastrichtuniversity.nl (J.C. Peters).
} 


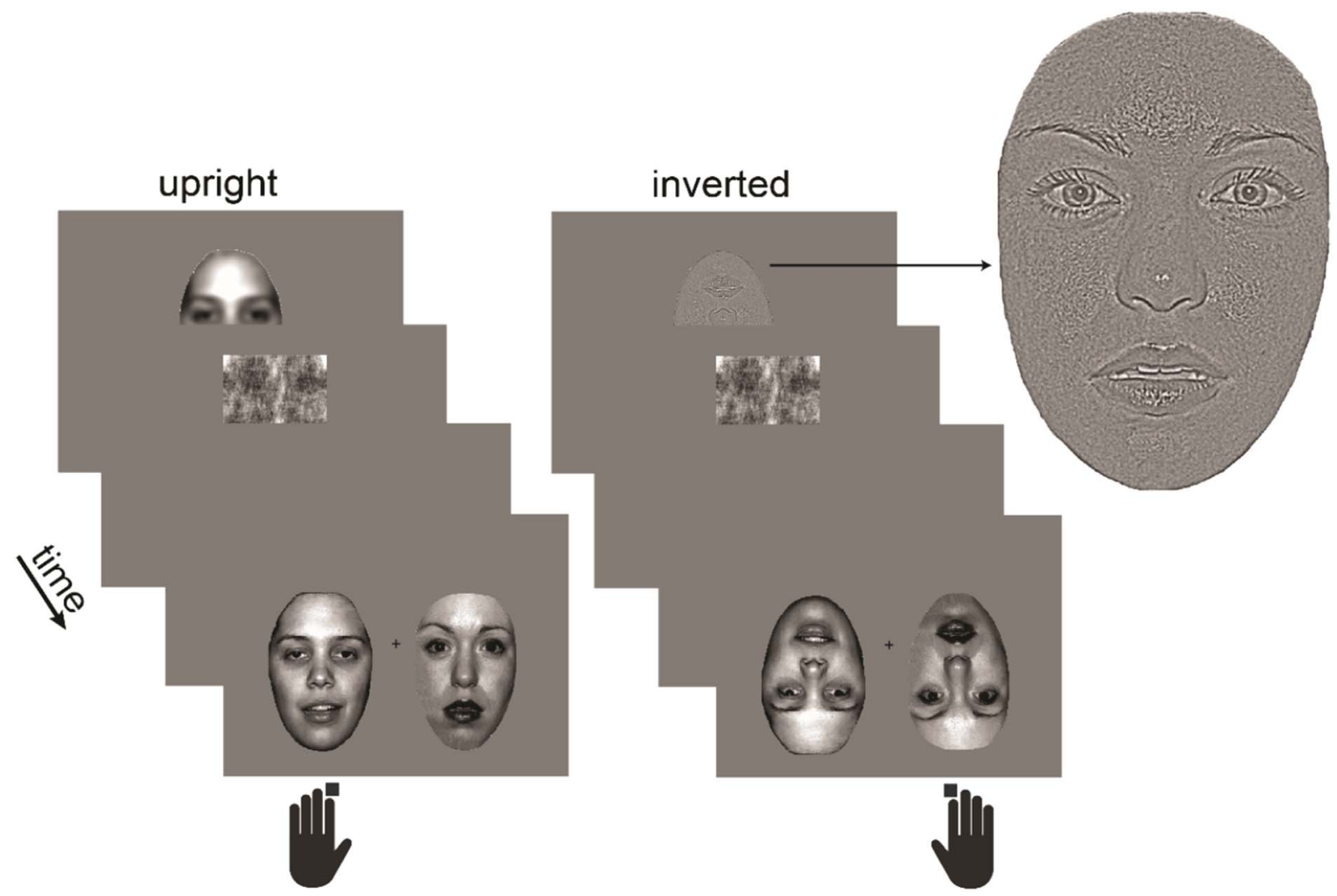

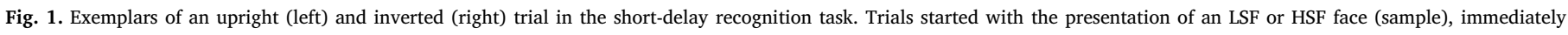

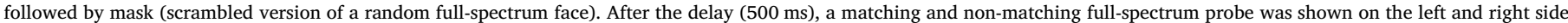

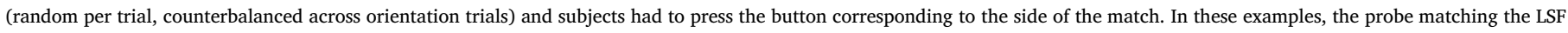

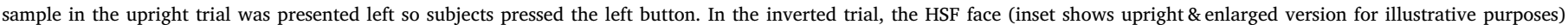
matched the probe on the right, requiring a right button response.

which of the two probe faces matched the sample face. When the probes differed in configural aspects (spatial relations between features, such as the metric distance between eyes), subjects were faster in discriminating low-pass filtered faces than high-pass filtered faces. In contrast, high-pass filtered faces provided an advantage when probes differed on local features. Thus, the presence of LSF content facilitated configural processing, whereas the availability of HSF information supported local feature processing. However in Goffaux et al.'s study, sample and probes faces were presented simultaneously until the subject responded. Hence, subjects could compare the sample and probes solely using perceptual information without the need to rely on memory processes (other than trans-saccadic memory). Thus, although Goffaux et al. (2005) provided important insights into the differential role of LSF versus HSF cues in face perception, it remains unclear whether face memory depends on similar divergent SF contributions. Although face memory and face perception are related, underlying processes could be biased to different SF bands: Face perception relies on LSF-based configural processing, which is useful to monitor fast and global changes, such as switches between emotional states or head turns. However, memorizing a face might require an additional focus on local feature details that contain specific information on facial identity. For example, encoding identity-specific, fine details such as eye contours, lip shape, or skin texture could help to keep a memory representation of a facial identity separate from other stored representations of resembling faces, which is essential for accurate recall of the appropriate facial identity. Such specific details are conveyed by HSF rather than LSF content. Therefore, unlike face perception, HSF information in faces might be as relevant for face memory as LSF content. The present study investigates this question by employing a paradigm akin to Goffaux et al. (2005), but with (short and long) memory delays between sample and probe presentations. In addition, low-pass and high-pass filtered faces were not only presented in upright orientation, but also in inverted orientation. Face inversion disrupts configural processing more strongly than the processing of local features (e.g., Goffaux, 2009; Rossion, 2008), while preserving intrinsic input properties. Therefore, manipulation of picture-plane orientation allows a well-controlled examination of the relative involvement of configural versus local feature processes. Face perception research showed the importance of LSF for configural processing. If (potential) contributions of LSF content to face memory were likewise attributable to the configural cues conveyed by this SF range, disruption of such cues by face inversion will have a particular strong impact on LSF-driven memory processes. In contrast, given that local feature processing is less affected by face inversion, inverting high-pass filtered faces might be less disruptive for face memory.

In addition to the role of SF in adult face memory, the present study also examines how SF-driven face processing changes during development, with a particular focus on the dynamic period during early adolescence. Children adopt a different SF processing strategy than adults, which might underlie their inefficiency in configural processing. Children below 10 perform poorly on face perception tasks that require the use of configural information (Mondloch, Le Grand, \& Maurer, 2002; Schwarzer, 2000). This might be related to the finding that, unlike adults, in 9-10-years-olds configural face processing is not driven by LSF content (Peters, Vlamings, \& Kemner, 2013). Interestingly, the same children who perform poorly on configural face perception tasks, perform well on tasks that entail the use of face features (Mondloch et al., 2002; Schwarzer, 2000; see Maurer, Le Grand, \& Mondloch, 2002 for review). This good performance, which in some cases reaches adult levels, might benefit from the preferred use of 
HSF instead of LSF content in (emotional) faces, as observed in children between 5 and 8 years old (Deruelle \& Fagot, 2005; Vlamings, Jonkman, \& Kemner, 2010). This bias toward HSF- over LSF-processing might result from the immaturity of the LSF pathway in children. The HSF processing is matured at 3-4 years (Adams \& Courage, 2002). In stark contrast, sensitivity for LSF is only fully matured in preadolescence (12/13-year-olds; Madrid \& Crognale, 2000). Nonetheless, even in 14-15-years-olds LSF-driven configural face processing is not matured yet (Peters et al., 2013), indicating that sufficient LSF sensitivity in preadolescence does not automatically bring about adequate LSF use in adolescent face processing. Face perception undergoes various dynamic changes in early adolescence: Several studies have revealed a general dip or plateau in the development of face processing skills at the onset of puberty (Carey, Diamond, \& Woods, 1980; Carey, 1992; Chung \& Thomson, 1995; Diamond, Carey, \& Back, 1983; Ellis, 1990; Flin, 1980; Lawrence et al., 2008). In this period, a reorganization of face perception appears to take place, as suggested by modulations in face processing strategies (Schwarzer, 2000) and neural changes in the face processing network (e.g., Itier \& Taylor, 2004). Investigations on face recognition in later phases of adolescence are scarce. However, psychophysical findings suggest that adolescents aged 14 or even older still make more errors than adults on some (emotional) face recognition tasks (Carey et al., 1980; Gur et al., 2012; Lawrence, Campbell, \& Skuse, 2015; Tottenham, Leon, \& Casey, 2006; see also Germine, Duchaine, \& Nakayama, 2011), indicating protracted maturation of face recognition abilities throughout adolescence.

Given the unknown influence of SF on face memory in adults, and the interesting dynamic changes in (SF-driven) face recognition in early adolescence, the goals of the present study were two-fold: Firstly, the study examined the role of SF content in matured delayed face recognition, by presenting faces with either exclusively LSF or HSF content to adults, and measuring recall performance on full-spectrum (FSF) versions of these faces after a short- or long-delay. If configural face cues (such as mouth-nose-eye distance) were essential for face recognition (such as for configural face perception, Goffaux et al., 2005), encoding LSF over HSF content in a face benefits subsequent recall of that particular face. In contrast, if local HSF-dependent features were important to store face identities in memory, an encoding advantage for HSF compared to LSF information is expected. Furthermore, we investigated whether any effects were specific for configural processing, by comparing short-delay recognition trials in which faces were presented in upright versus inverted orientation. The second goal was to assess how the relative importance of LSF and HSF cues for face memory might change during early adolescence. The onset of puberty is characterized by various hormonal, neuronal, and cognitive changes, which likely contribute to the halt in the improvement of face perception skills (for review, see Chung \& Thomson, 1995). This might coincide with a reorganization of face processing that promotes a more configural-than featural-oriented face processing style (Mondloch et al., 2002), in line with the rising preference for LSF over HSF information in faces. To investigate this interesting developmental period, we compared face memory performance in females on the verge of (pre-) adolescence (9-10-year-olds) to females in an early (12-13-year-olds) and later (15-16-year-olds) stages of adolescence, and to young adult females (21-32-year-olds). Our study only included females to avoid gender-related variations in pubertal stages, which affects face perception performance (see below). If the role of SF in face memory follows similar developmental tendencies as face perception, the differential use of cues in LSF and HSF content should become more apparent with increasing age.

\section{Methods}

\subsection{Participants}

Healthy females with normal or corrected-to-normal visual acuity were divided in four groups according to their age: 1 ) children between 9-10 years $(n=15$; mean age $=9.7$ years; age range 9.3-10.5 years), adolescents between 2$) 12-13$ years $(n=14$; mean age $=13.0$ years; age range 12.4-13.8 years; early adolescence) and 3) 15-16 years $(n=15$; mean age $=16.2$ years; age range $15.7-16.9$ years; late adolescence), and 4) young adults between 21 and 32 years ( $n=14$; mean age $=25.4$ years; age range $21.2-32.6$ years). The median age per age group was $9.8,13.0,16.2$, and 22.8 years, respectively. We only included females in our study, to avoid gender-related variations in puberty affecting face recognition performance: Males in early adolescence show lower face recognition performance than females (McGivern, Andersen, Byrd, Mutter, \& Reilly, 2002), in line with their later onset of puberty (Tanner \& Whitehouse, 1976). One child performed the short-delay recognition task around chance level and was therefore excluded from further analyses. Furthermore, one adolescent from the 12-13-years-olds group did not participate in the long-delay recognition task. Participants in these four groups were recruited from a primary school, high school, and university in The Netherlands. Participants (adolescents, and adults) and parents (children and adolescents) gave their written informed consent to participate and received a small self-selected toy (children) or financial reward. All procedures were approved by the ethics committee of the Faculty Psychology of Maastricht University and are in accordance with the Declaration of Helsinki.

\subsection{Experimental procedure and task design}

Subjects were individually tested in front of a $21 \mathrm{in.} \mathrm{LCD} \mathrm{monitor} \mathrm{in}$ a dimly lit room. They were instructed to maintain a fixed viewing distance $(106 \mathrm{~cm})$ from the screen, which was monitored by the experimenter throughout the measurement. Each subject performed both a short and long-delay face recognition task in which sample (encoding phase) faces have to be matched to probe faces (retrieval phase). In both tasks, samples had only HSF or LSF content, whereas the probes were unfiltered (i.e., full-spectrum; FSF). Participant responded using two buttons on a 6-button (15-16-years-olds) or 2-button (other age groups) response pad.

\subsection{Stimuli}

Grayscale front-view photographs of male (50\%) and female (50\%) faces with a neutral expression were selected from the NimStim Face Set (Tottenham et al., 2009) and a stimulus dataset created by Goffaux (Goffaux, 2009) and were trimmed to remove neck and hairline. Faces in both datasets were similar in global face characteristics and provided a sufficient number of unique face identities to minimize learning effects and/or interference within and between tasks. All stimuli $\left(6.9^{\circ} \times 4.9^{\circ}\right)$ were equal in luminance and contrast to control for lowlevel perceptual differences, and were presented on a homogenous gray background. The spatial frequency content of sample faces was either unfiltered, or filtered with a high-pass (HSF; $\geq 6$ cycles/deg. of visual angle) or low-pass (LSF; $\leq 2$ cycles/deg. of visual angle) cut-off. In the short-delay tasks, we used a HSF, LSF and FSF version of 28 faces (50\% male). In addition, a scrambled mask was created of each FSF face in this task, by scrambling the phase of the images in the Fourier domain via random permutation, which preserves orientation content (Dakin, Hess, Ledgeway, \& Achtman, 2002). For the sample stimuli of the longdelay task, we created an LSF version of 8 different faces (50\% male) and an HSF version of 8 other faces ( $50 \%$ male). FSF versions of these faces were used as 'old' probes whereas 8 new FSF faces functioned as 'new' probes.

\subsection{Short-delay recognition task}

Each trial started with the presentation of a HSF or LSF face for $300 \mathrm{~ms}$, immediately followed by a randomly chosen scrambled mask (for $70 \mathrm{~ms}$ ). The mask was replaced by a fixation cross in the middle of 


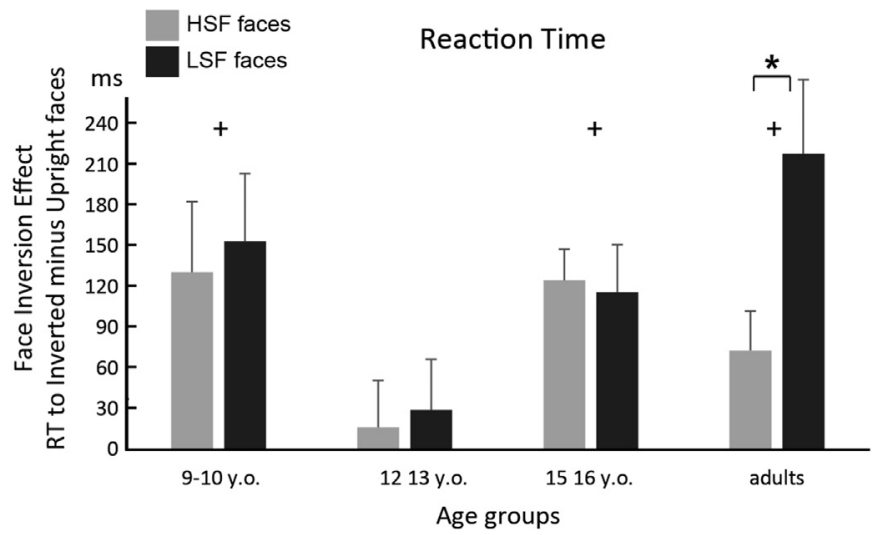

Fig. 2. Bar graphs of the mean RT face inversion effect (i.e., RT to Inverted minus Upright faces) per age group (clusters) and spatial frequency (colours). Plus signs indicate a significant main effect of orientation (FIE; $p<0.02$ ), whereas asterisks on top of connection lines indicate a significant interaction between orientation and SF $(\mathrm{p}<0.002)$ in the age-group specific ANOVAs. Error bars indicate standard error of mean.

the screen for $500 \mathrm{~ms}$. The mask forced subjects to maintain the image in short-term memory instead of iconic memory. After the delay, a probe stimulus was shown in the lower left, and another in the right visual field (at $4.9^{\circ}$ eccentricity). One of the probes was the FSF version of the preceding sample (match), whereas the other FSF face had a different facial identity (non-match). The randomly selected nonmatching probe always had the same gender as the sample stimulus, to avoid any memory strategies based on face gender. The match and nonmatch sample could occur with an equal probability (counterbalanced across orientation trials) on the left or right side, and subjects had to press the corresponding left or right button. The probe display was shown until response (but for max. $3 \mathrm{~s}$ ) and followed by presentation of the fixation cross (i.e., $2 \mathrm{~s}$ inter-trial interval). Subject performed four blocks of 28 trials each, in which the LSF or HSF (50\%) version of each of the 28 face identities was shown. Faces were shown with inverted orientation in two blocks, which were interleaved with blocks of upright faces. The task started with verbal instructions followed by exemplar trials with inverted and upright trials of HSF and LSF faces performed by the experimenter. Subsequently, the participant practiced one trial. The task was similar for each age group, except that the 9-10years-olds received three practice trials and had max. $6 \mathrm{~s}$ instead of $3 \mathrm{~s}$ to respond.

\subsection{Long-delay recognition task}

In the encoding phase, $8 \mathrm{LSF}$ and 8 HSF faces were shown successively for $2 \mathrm{~s}$ each $(0.5 \mathrm{~s}$ inter-stimulus interval; ISI) and participants were instructed to memorize the stimuli. After $10 \mathrm{~min}, 8$ (randomly selected) FSF versions of the sample stimuli (old) and 8 new FSF stimuli (new) were sequentially presented for $2 \mathrm{~s}$ ( $1 \mathrm{~s} \mathrm{ISI)}$ and subjects have to indicate for each probe whether it was old or new. The buttons used for the response 'old' versus 'new' were counterbalanced across subjects. The task was similar for each age group, except that the 9-10-years-olds received one practice trial, and ISI between probe stimuli was $2 \mathrm{~s}$ instead of $1 \mathrm{~s}$.

\subsection{Data analysis}

For the short-delay recognition task, correct reaction times and accuracy were subjected to separate repeated-measures ANOVAs with Spatial Frequency (LSF, HSF) and Orientation (upright, inverted) as within-subject factors and Age Group as between-subject factor. For one early adolescent, missing values of the inverted face conditions were replaced by the age-group-specific condition means (using the replace missing values by estimation of the series mean procedure in SPSS). For the long-delay recognition task, similar ANOVAs were performed but with spatial frequency (HSF-old and LSF-old) as within- and age group as between-subject factor. Only correct reaction times between two standard deviations above and below the subject- and condition-specific mean were included. This outlier removal procedure equalized the number or included trials between subjects and conditions, as reflected by the number of trials removed for each of the different age-groups: 9-10 -years-olds (mean: 1.05; range: 0.50-1.75), 12-13 -years-olds (mean: 1.09; range: $0.50-1.50$ ), 15-16 -years-olds (mean: 1.15 ; range: 0.50-2.00), 21-32 -years-olds (mean: 1.11; range: 0.25-1.75). Effect sizes of reported effects were estimated using partial eta squared $\left(\eta^{2}\right)$. This is a standard metric in repeated-measure designs that estimates the magnitude of a given effect by quantifying the percentage of variance explained by a given factor when excluding the contribution of intersubject variance.

Main effects are not discussed when they interact with other factors. Instead, subsequently performed posthoc, Bonferroni-corrected paired $t$-tests are reported. Note that shown $t$-tests statistics report Bonferronicorrected $p$-values, but original degrees of freedom. Main effects (of non-interacting factors) and interactions that are not reported did not reach significance. In addition to the ANOVAs, RTs to upright faces with LSF and HSF content were subjected to age-group specific planned $t$-tests, to specifically test whether we could replicate across age groups the speeded responses to LSF faces as observed in adults by Goffaux et al. (2005). All statistical analyses were performed in SPSS 24 (SPSS INC, Chicago, IL).

\section{Results}

\subsection{Short-delay recognition task}

Mean reaction time (RT; Fig. 2) was influenced by Age Group (F $\left.(3,53)=13.19 ; \mathrm{p}<0.00001 ; \eta^{2}=0.43\right)$. Posthoc $t$-tests showed that the 15-16-years-olds had faster responses than the other age groups (all p's $<0.01$ ), which otherwise did not differ (all p's $>0.1$ ). However, 15-16-years-olds used a different response button box than the other three age groups, which might have contributed to overall RT differences. Therefore, we exclude the 15-16-years-olds from the mixed ANOVA and analyse this age group separately. The 15-16-years-olds adolescents only showed a main effect of Orientation, with faster responses to upright compared to inverted faces $(\mathrm{F}(1,14)=19.32$, $\left.\mathrm{p}=0.001 ; \eta^{2}=0.58\right)$.

The ANOVA encompassing the other three age groups revealed a three-way interaction between Age Group, Orientation and SF $(F(2,39)$ $\left.=4.20, \mathrm{p}=0.02 ; \eta^{2}=0.18\right)$. This interaction effect was further tested in repeated-measures ANOVAs per age group with Spatial Frequency (LSF, HSF) and Orientation (upright, inverted) as factors. Children (F $\left.(1,13)=9.19, \mathrm{p}=0.01 ; \eta^{2}=0.41\right)$, and adults $(\mathrm{F}(1,13)=12.93$, $\mathrm{p}=0.003 ; \eta^{2}=0.50$ ) had faster responses to upright compared to inverted faces. In contrast, 12-13-years-olds did not show such a FIE ( $\mathrm{p}>0.30$ ). Importantly, in adults orientation was qualified by SF (F $\left.(1,13)=17.97, p=0.001 ; \eta^{2}=0.58\right)$. When faces contained LSF content, RT was $218.30 \mathrm{~ms}$ faster for upright than inverted faces (t $\mathrm{t}(13)$ $=3.98 ; \mathrm{p}=0.004)$. In contrast, HSF faces showed only a trend toward faster responses for upright compared to inverted faces (mean difference of $72.96 \mathrm{~ms} ; \mathrm{t}(13)=2.49 ; \mathrm{p}=0.06)$.

Finally, adults $(\mathrm{t}(13)=2.26 ; \mathrm{p}=0.04)$ were on average $51.10 \mathrm{~ms}$ faster for recognizing upright LSF compared to upright HSF faces, in contrast to the other age-groups (all p's $>0.3$ ).

Accuracy differed across age groups $(\mathrm{F}(3,53)=10.40$; $\left.\mathrm{p}=0.00002 ; \eta^{2}=0.37\right)$. As illustrated in Fig. 3, accuracy showed a monotonic linear increase $(\mathrm{p}<0.00001)$ with increasing age group. Bonferroni-corrected $t$-tests showed that all age groups differed significantly (all p's $<0.012$ ), except for directly succeeding age-groups (all p's $>0.1$ ). Furthermore, accuracy was influenced by Orientation $\left(F(1,53)=93.3 ; p<0.00001 ; \eta^{2}=0.64\right)$, with higher accuracy for 


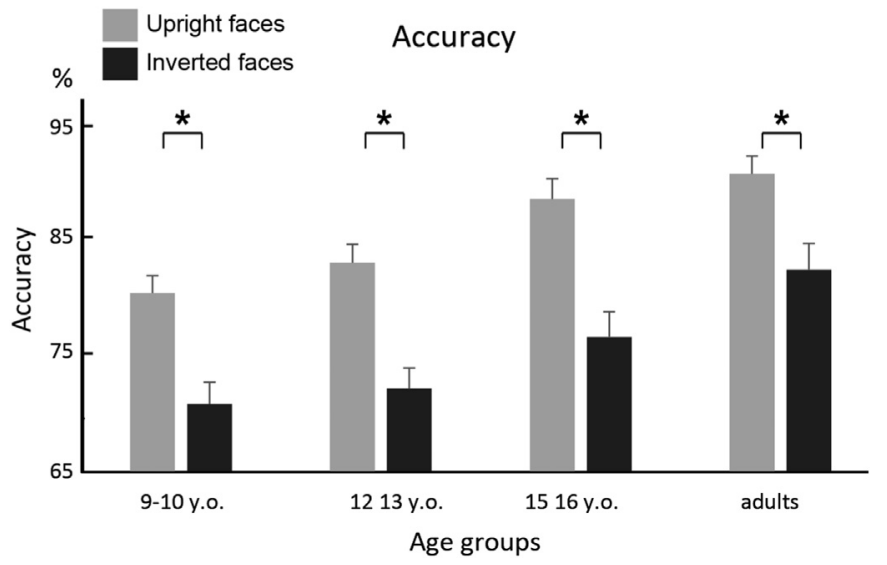

Fig. 3. Bar graphs of mean accuracy per age group (clusters) and orientation (colours). Asterisks on top of connection lines indicate a significant main effect of orientation $(\mathrm{p}<0.00001)$. Error bars indicate standard error of mean.

upright compared to inverted faces.

\subsection{Long-delay recognition task}

Mean accuracies revealed that this task was too difficult for the 9-10-year-olds, as they on average scored at chance level (mean accuracy $50.61 \%$; s.e. $3.78 \%$ ). Therefore, this age group was excluded from further analyses. Although accuracy in the other age groups was above chance level, it was low (63.33\%; s.e. $3.20 \%$ ), revealing that the task was relatively difficult. RT was not influenced by any factor (p's $>0.36$ ). Likewise, accuracy did not differ across age groups nor did it interact with SF (p's > 0.85). However, there was a main effect of $\mathrm{SF}\left(\mathrm{F}(1,39)=4.59, \mathrm{p}=0.04 ; \eta^{2}=0.11\right)$, revealing a higher accuracy for LSF (mean $68.60 \%$; s.e. $3.79 \%$ ) compared to HSF (mean $58.00 \%$; s.e. $4.30 \%$ ) faces.

\section{Discussion}

The present study investigated the differential role of information in the low versus high spatial frequency (SF) ranges in face recognition during childhood, adolescence, and adulthood. We manipulated SF content of (sample) faces in the encoding phase to examine how SF availability affected short- and long-term recall in females. In addition, we studied whether SF influences were specific for configural processing by assessing the Face Inversion Effect (FIE) in the short-delay task.

Results showed that in the long-delay task, accuracy was higher when the sample face contained LSF compared to HSF information. Note that in this task, all samples were presented first. Only after a long delay, all probes were presented in succession. Thus, in the short encoding phase, a number of different facial identities had to be stored in a format robust to interference of other face representations. This design particularly invites the storage of identity-specific, fine features that could help to distinguish a facial identity from other resembling faces. Given that such specific details (e.g., eye contours) are conveyed by HSF information, availability of HSF content might be more important for accurate face encoding here, compared to tasks probing short-term face memory (in which no immediate interference is expected) or face perception in general. Nevertheless, results clearly showed that accuracy was higher when LSF information was available for memory encoding than when sample faces contained HSF information.

Moreover, adults, 12-13-year-olds, and 15-16-year-olds showed a similar recall advantage for encoding LSF compared to HSF faces, suggesting that the availability of LSF information facilitates the encoding of faces for long-term memorization in both adolescent as well as adult females. However, null-effects should always be interpreted with caution. More subtle age-dependent changes in the strength of the LSF encoding advantage might have been obscured by the relatively small age group sizes.

In the short-delay task, the effect of LSF was influenced by both face inversion as well as age: Only adults showed faster responses when LSF instead of HSF cues were present in the (upright) faces encoded into memory. Goffaux et al. (2005) showed a similar speeded response to upright LSF faces when adults performed a face perception task that strongly relied on configural processing (i.e., assessing spatial relations between features). In contrast, an advantage for HSF faces was revealed when the task required processing of local, individual features. This, and other research (e.g., Goffaux \& Rossion, 2006; Sergent, 1986), suggests that LSF content in faces conveys configural cues, whereas featural details are extracted from HSF information. In Goffaux et al. (2005), both the sample and probe faces were shown at the same time and stayed on the screen until subject's response, thereby eliminating any (non-trans-saccadic) memory demands In contrast, in the present study the sample face was presented first, followed by a mask to erase visual iconic memory. The probe faces were only presented after a subsequent delay, which required subjects to encode the face in visual memory. Despite this memory delay, our findings resembled the results of Goffaux et al.'s configural face perception task. Thereby, the present observation of speeded recognition for faces in which LSF content was available during encoding, extends Goffaux et al.'s finding from face perception to the domain of face memory. The LSF advantage observed in both studies, suggests that configural cues are important for the effective storage and recall of faces. This interpretation is corroborated by the finding that inversion of LSF sample faces resulted in much slower recognition (i.e., $218 \mathrm{~ms}$ slower than on upright trials).This strong impact of face inversion on the recollection of LSF sample faces, likely results from the obliteration of configural cues (Goffaux, 2009). In sum, the faster recall of (upright) LSF faces than HSF sample faces, and the highly disruptive effect of inversion on LSF-(but not HSF-)driven face encoding, suggest a relative important contribution of configural cues (compared to featural cues) to a mode of storing faces that instigates fast recall.

In contrast to adults, the speeded response to upright compared to inverted faces was equally strong for LSF and HSF faces in both children as well as 15-16-year-olds. The lack of advantage for faces with LSF content - even in 15-16-year-olds - is in line with previous ERP findings showing that in-depth, LSF-driven configural processing has a protracted maturational course throughout adolescence (Peters et al., 2013). Our results also match the lower recognition performance of 13-17-year-olds adolescents compared to adults, on discrimination tasks in which faces and houses were only shown for $17 \mathrm{~ms}$ (Tottenham et al., 2006). LSF content in faces is faster available than HSF content (e.g., Peters et al., 2013; see also Breitmeyer \& Ganz, 1977), and plays an essential role in fast visual processing (e.g., Parker, Lishman, \& Hughes, 1997). The immature LSF-driven face processing in adolescence might therefore not only affect more general face perception and memory processes, but might also influence mechanisms involved in fast vision.

Although not affected by SF content, children and 15-16-year-olds did show a general FIE. Thus, already around the age of 9-10 year, delayed recognition is faster (and better) for upright compared to inverted faces, in line with face perception studies showing FIEs in 9-10year-olds (e.g., Carey \& Diamond, 1994). Interestingly, the RTs of our 12-13-years-olds were not affected by face inversion at all. This lack of advantage for upright faces might reflect the lack of improvement, or even a decrease, in face processing abilities at the onset of puberty (Carey et al., 1980; Carey, 1992; Chung \& Thomson, 1995; Diamond et al., 1983; Ellis, 1990; Flin, 1980; Lawrence et al., 2008). At this age, a reorganization of face perception appears to take place, which is associated with accompanying neurological changes in face processing areas. For example, the morphology of the face-selective N170 starts to merge from a bifid into a single ERP component (Itier \& Taylor, 2004; 
Peters et al., 2013). This neural reorganization, together with other neuronal (Giedd et al., 1999; Passarotti, Smith, DeLano, \& Huang, 2007), hormonal, and cognitive changes (for review, see Carey, 1992; Chung \& Thomson, 1995) reduces face recognition in early puberty, which recovers in mid-adolescence. Interestingly, a comparable performance dip at age 13 has been reported for recognition of flags and houses (Flin, 1985), and even voice recognition (Mann, Diamond, \& Carey, 1979), suggesting a general reorganization of object recognition. Further studies could use these co-occurring pubertal dips to gain more insights into the (cognitive and neural) nature of this reorganization. Puberty has a later onset in boys than girls (Tanner and Whitehouse, 1976), which contribute to gender-related differences in face recognition in early adolescence (Lawrence, Campbell, \& Skuse, 2015; McClure, 2000; McGivern et al., 2002). To avoid such genderrelated variations in puberty, we only included females in our study. Future research can investigate whether males show a similar SF-independent dip in performance, similar to the females participating in our study but occurring at a later age. In addition, such studies could also further explore other gender-related differences in face processing that might emerge at this age (McClure, 2000).

Finally, accuracy in the short-delay task increased across age groups, in line with other studies showing improvements in face recognition throughout adolescence (e.g., Gur et al., 2012). Furthermore, accuracy was higher for upright compared to inverted faces, corroborating previous results reporting such FIEs from late childhood on (e.g., Crookes \& McKone, 2009).

Results of both tasks suggest that face recognition in adult females depends more strongly on LSF than HSF information: When faces contain LSF rather than HSF information, long-term recall accuracy is higher, and short-term recall is faster. This LSF advantage cannot be caused by low-level stimulus differences like contrast and luminance, since HSF and LSF faces were equalized for low-level characteristics. Moreover, face inversion provided an additional confirmation of the importance of configural cues conveyed by LSF content for high-level processes underlying the encoding of faces in memory. That, is the recognition of upright compared to inverted faces was only faster in trials where LSF content was available during encoding. Since face inversion preserves intrinsic input characteristics, the LSF advantage has to stem from higher-level, observer-dependent interactions such as configural processing rather than low-level visual processes. Given that configural processing is disrupted by face inversion (e.g., Rossion, 2008), the large FIE for LSF (but not for HSF) faces is likely caused by the unavailability of configural cues for LSF-driven encoding of inverted faces. Together, these results suggests that the memory encoding advantage for LSF over HSF faces observed in adult females is based on configural information in LSF ranges. The superior face recognition performance when faces contained configural LSF cues rather than featural HSF cues, does however by no means indicate that LSF information is the only (or most essential) SF range for adequate recognition. Likely, face memory improves when information from intermediate SF (iSF) ranges would be added to LSF faces (Gold, Bennett, \& Sekuler, 1999). Further research could further explore the importance of SF content in face recognition, by mutually comparing recognition performance on unfiltered faces and filtered faces with LSF, iSF, and LSF + iSF content.

In contrast to adults, children and adolescents (both the early and late group) did not show an LSF advantage for short-term recall. Although we only measured females, this results agrees with the slow neural maturation of LSF-driven face perception as observed in a mixedgender developmental study (Peters et al., 2013). In line with the importance of LSF information for configural processing (e.g., Goffaux \& Rossion, 2006; Goffaux et al., 2005; Sergent, 1986) and the slow maturation of the LSF pathway, psychophysical studies observed a much slower development of configural than featural face perception (e.g., Maurer et al., 2002; Mondloch et al., 2002; Schwarzer, 2000). This protracted maturation course of configural face perception results from an ongoing neural reorganization by progressive proliferation (Golarai, Liberman, Yoon, \& Grill-Spector, 2010; Golarai et al., 2007; Gomez et al., 2017) and functional tuning (Passarotti et al., 2007) of the neural face network throughout adolescence (see CohenKadosh \& Johnson, 2007; Cohen Kadosh, 2012; Grill-Spector, Golarai, \& Gabrieli, 2008 for reviews). The gain in face expertise as adolescents grow older (which, speculatively, might be accelerated by the increased importance of social interactions), might also contribute to improvements in the maturation of LSF-driven face memory. Suggestions in this direction come from a psychophysical study revealing a relation between experience and effective use of LSF cues in objects of expertise (Viggiano, Righi, \& Galli, 2006): Compared to novices, toolexperts needed less additional information in the middle and high SF spectrum of pictures for correct tool identification. Likewise, increased face expertise might also aid the adequate use of LSF information for face recognition.

In sum, our results show that, akin to face perception, face memory in adult females improves when LSF content is made available in face images. This is true for recall after a short or longer delay. This similarity might seem unsurprising, given that face recognition strongly depends on face perception. However, encoding faces in memory, and subsequent recall of these faces, entails more cognitive operations that might benefit from other (or additional) face information than that required for perception. Moreover, neural mechanisms underlying face perception and memory are not fully overlapping. Lesion patients can for example show an impairment in face memory, despite normal performance on face discrimination tasks (so-called prosopamnesia; Tippett, Miller, \& Farah, 2000; Williams, Berberovic, \& Mattingley, 2007).

Similar to adults, adolescents' long-term face recall benefitted from LSF face content. However, adolescents did not show an LSF advantage for face recall in the short-delay task. This suggests that similar to the face perception network, neural face recognition mechanisms have protracted maturational courses into adolescence, which are influenced by SF information. In adolescence, sensitivity to configural LSF cues is developed, which aids not only face perception but also face memorization. Our study did not include 17-21-year-olds and males, and therefore results cannot be generalized to final stages of adolescence or to male adolescence. Future research could study whether the current results extend to the male or 17-21-year-old population. Moreover, further work could explore SF-dependent face memorization processes in neurodevelopmental disorders. For example, how impaired configural face perception following early visual deprivation (Le Grand, Mondloch, Maurer, \& Brent, 2001) affects SF-dependent face memory. Furthermore, it would be interesting to examine whether the inadequate, LSF-based face perception mechanisms observed in Autism Spectrum Disorder (ASD; Deruelle, Rondan, Salle-Collemiche, BastardRosset, \& Da Fonséca, 2008; Deruelle, Rondan, Gepner, \& Tardif, 2004; Johnson, 2005; Vlamings, Jonkman, \& Kemner, 2010; Vlamings, Jonkman, van Daalen, et al., 2010) contribute to the atypical face memory development in adolescents with ASD (O'Hearn, Schroer, Minshew, \& Luna, 2010). If inefficient processing of LSF content indeed hampers face memory performance in such disorders, it might be worthwhile to investigate whether face memory skills can be improved by training-induced increases in LSF sensitivity (Peters, van den Boomen, \& Kemner, 2017).

\section{Acknowledgements}

The authors thank participants and their parents. In addition we are grateful to Carlijn van den Boomen and Anniek Oost for help in data acquisition of the 9-10- and 12-13-year-olds respectively. Furthermore, we thank Valerie Goffaux for her helpful suggestions on the experimental design and her contribution to the stimulus dataset. Finally, we want to thank two anonymous reviewers for their useful comments. This research was supported by an NWO-VICI (453-07-004) grant to CK. 


\section{References}

Adams, J. A., \& Courage, M. L. (2002). Using a single test to measure human contrast sensitivity from early childhood to maturity. Vision Research, 42, 1205-1210.

Bar, M. (2004). Visual objects in context. Nature Reviews Neuroscience, 5, 617-629.

Breitmeyer, B. G., \& Ganz, L. (1977). Temporal studies with flashed gratings: Inferences about human transient and sustained channels. Vision Research, 17, 861-865.

Carey, S. (1992). Becoming a face expert. Philosophical Transactions of the Royal Society of London B, 335, 95-102 (discussion 102-103).

Carey, S., \& Diamond, R. (1994). Are faces perceived as configurations more by adults than by children? Visual Cognition, 1, 253-274.

Carey, S., Diamond, R., \& Woods, B. (1980). Development of face recognition: A maturational component? Developmental Psychology, 16, 257-269.

Chung, M. S., \& Thomson, D. M. (1995). Development of face recognition. British Journal of Psychology, 86, 55-87.

Cohen Kadosh, K. (2012). Differing processing abilities for specific face properties in midchildhood and adulthood. Frontiers in Psychology, 2, 400.

Cohen-Kadosh, K., \& Johnson, M. H. (2007). Developing a cortex specialized for face perception. Trends in Cognitive Sciences, 11, 267-269.

Crookes, K., \& McKone, E. (2009). Early maturity of face recognition: No childhood development of holistic processing, novel face encoding, or face-space. Cognition, 111, 219-247.

Dakin, S. C., Hess, R. F., Ledgeway, T., \& Achtman, R. L. (2002). What causes nonmonotonic tuning of fMRI response to noisy images? Current Biology, 12, R476-R477.

Deruelle, C., \& Fagot, J. (2005). Categorizing facial identities, emotions, and genders: Attention to high- and low-spatial frequencies by children and adults. Journal of Experimental Psychology, 90, 172-184.

Deruelle, C., Rondan, C., Gepner, B., \& Tardif, C. (2004). Spatial frequency and face processing in children with autism and Asperger syndrome. Journal of Autism and Developmental Disorders, 34, 199-210.

Deruelle, C., Rondan, C., Salle-Collemiche, X., Bastard-Rosset, D., \& Da Fonséca, D. (2008). Attention to low- and high-spatial frequencies in categorizing facial identities, emotions and gender in children with autism. Brain and Cognition, 66, 115-123.

Diamond, R., Carey, S., \& Back, K. J. (1983). Genetic influences on the development of spatial skills during early adolescence. Cognition, 13, 167-185.

Ellis, H. D. (1990). Developmental trends in face recognition. The Psychologist, 3 , 114-119.

Flin, R. H. (1980). Age effects in children's memory for unfamiliar faces. Developmental Psychology, 16, 373-374.

Flin, R. H. (1985). Development of visual memory: An early adolescent regression. Journal of Early Adolescence, 5, 259-266.

Germine, L. T., Duchaine, B., \& Nakayama, K. (2011). Where cognitive development and aging meet: face learning ability peaks after age 30. Cognition, 118, 201-210. http:// dx.doi.org/10.1016/j.cognition.2010.11.002.

Giedd, J. N., Blumenthal, J., Jeffries, N. O., Castellanos, F. X., Liu, H., Zijdenbos, A., . Rapoport, J. L. (1999). Brain development during childhood and adolescence: A longitudinal MRI study. Nature Neuroscience, 2, 861-863.

Goffaux, V. (2009). Spatial interactions in upright and inverted faces: Re-exploration of spatial scale influence. Vision Research, 49, 774-781.

Goffaux, V., Hault, B., Michel, C., Vuong, Q. C., \& Rossion, B. (2005). The respective role of low and high spatial frequencies in supporting configural and featural processing of faces. Perception, 34, 77-86.

Goffaux, V., Peters, J., Haubrechts, J., Schiltz, C., Jansma, B., \& Goebel, R. (2011). From coarse to fine? Spatial and temporal dynamics of cortical face processing. Cerebral Cortex, 21, 467-476.

Goffaux, V., \& Rossion, B. (2006). Faces are "spatial"-holistic face perception is supported by low spatial frequencies. Journal of Experimental Psychology. Human Perception and Performance, 32, 1023-1039.

Golarai, G., Ghahremani, D. G., Whitfield-Gabrieli, S., Reiss, A., Eberhardt, J. L., Gabrieli, J. D., \& Grill-Spector, K. (2007). Differential development of high-level visual cortex correlates with category-specific recognition memory. Nature Neuroscience, 10, $512-522$.

Golarai, G., Liberman, A., Yoon, J. M. D., \& Grill-Spector, K. (2010). Differential development of the ventral visual cortex extends through adolescence. Frontiers in Human Neuroscience, 3, 80 .

Gold, J., Bennett, P. J., \& Sekuler, A. B. (1999). Identification of band-pass filtered letters and faces by human and ideal observers. Vision Research, 39, 3537-3560.

Gomez, J., Barnett, M. A., Natu, V., Mezer, A., Palomero-Gallagher, N., Weiner, K. S., .. Grill-Spector, K. (2017). Microstructural proliferation in human cortex is coupled with the development of face processing. Science, 355, 68-71.

Gur, R. C., et al. (2012). Age group and sex differences in performance on a computerized neurocognitive battery in children age 8-21. Neuropsychology, 26, 251-265. http:// dx.doi.org/10.1037/a0026712.

Grill-Spector, K., Golarai, G., \& Gabrieli, J. (2008). Developmental neuroimaging of the human ventral visual cortex. Trends in Cognitive Sciences, 12, 152-162.

Itier, R. J., \& Taylor, M. J. (2004). Face recognition memory and configural processing: A developmental ERP study using upright, inverted, and contrast-reversed faces.
Journal of Cognitive Neuroscience, 16, 487-502.

Johnson, M. H. (2005). Subcortical face processing. Nature Reviews Neuroscience, 6, 766-774.

Lawrence, K., Bernstein, D., Pearson, R., Mandy, W., Campbell, R., \& Skuse, D. (2008). Changing abilities in recognition of unfamiliar face photographs through childhood and adolescence: Performance on a test of non-verbal immediate memory

(Warrington RMF) from 6 to 16 years. Journal of Neuropsychology, 2, 27-45.

Lawrence, K., Campbell, R., \& Skuse, D. (2015). Age, gender, and puberty influence the development of facial emotion recognition. Frontiers in Psychology, 6, 761. http://dx. doi.org/10.3389/fpsyg.2015.00761.

Le Grand, R., Mondloch, C. J., Maurer, D., \& Brent, H. P. (2001). Early visual experience and face processing. Nature, 410, 890.

Madrid, M., \& Crognale, M. A. (2000). Long-term maturation of visual pathways. Visual Neuroscience, 17, 831-837.

Mann, V. A., Diamond, R., \& Carey, S. (1979). Development of voice recognition: Parallels with face recognition. Journal of Experimental Child Psychology, 27, 153-164.

Maurer, D., Le Grand, R., \& Mondloch, C. J. (2002). The many faces of configural processing. Trends in Cognitive Sciences, 6, 255-260.

McClure, E. B. (2000). A meta-analytic review of sex differences in facial expression processing and their development in infants, children, and adolescents. Psychological Bulletin, 126(3), 424-453.

McGivern, R. F., Andersen, J., Byrd, D., Mutter, K. L., \& Reilly, J. (2002). Cognitive efficiency on a match to sample task decreases at the onset of puberty in children. Brain and Cognition, 50, 73-89.

Mondloch, C. J., Le Grand, R., \& Maurer, D. (2002). Configural face processing develops more slowly than featural face processing. Perception, 31, 553-566.

O'Hearn, K., Schroer, E., Minshew, N., \& Luna, B. (2010). Lack of developmental improvement on a face memory task during adolescence in autism. Neuropsychologia, 48, 3955-3960. http://dx.doi.org/10.1016/j.neuropsychologia.2010.08.024.

Parker, D. M., Lishman, J. R., \& Hughes, J. (1997). Evidence for the view that temporospatial integration in vision is temporally anisotropic. Perception, 26, 169-180.

Passarotti, A. M., Smith, J., DeLano, M., \& Huang, J. (2007). Developmental differences in the neural bases of the face inversion effect show progressive tuning of face-selective regions to the upright orientation. NeuroImage, 34, 1708-1722.

Peters, J. C., van den Boomen, C., \& Kemner, C. (2017). Spatial frequency training modulates neural face processing: Learning transfers from low- to high-level visual features. Frontiers in Human Neuroscience, 11, 1.

Peters, J. C., Vlamings, P., \& Kemner, C. (2013). Neural processing of high and low spatial frequency information in faces changes across development: Qualitative changes in face processing during adolescence. European Journal of Neuroscience, 37, 1448-1457.

Rossion, B. (2008). Picture-plane inversion leads to qualitative changes of face perception. Acta Psychologica, 128, 274-289.

Ruiz-Soler, M., \& Beltran, F. S. (2006). Face perception: An integrative review of the role of spatial frequencies. Psychological Research, 70, 273-292.

Schwarzer, G. (2000). Development of face processing: The effect of face inversion. Child Development, 712, 391-401.

Sergent, J. (1984). An investigation into component and configural processes underlying face perception. British Journal of Psychology, 75, 221-242.

Sergent, J. (1986). Microgenesis of face perception. In H. D. Ellis, M. A. Jeeves, F. Newcombe, \& A. M. Young (Eds.), Aspects of face processing (pp. 17-33). Dordrecht: Martinus Nijhoff.

Tanner, J. M., \& Whitehouse, R. H. (1976). Clinical longitudinal standards for height, weight, height velocity, weight velocity, and stages of puberty. Archives of Disease of Childhood, 51, 170-179.

Tippett, L. J., Miller, L. A., \& Farah, M. J. (2000). Prosopamnesia: A selective impairment in face learning. Cognitive Neuropsychology, 17, 241-255.

Tottenham, N., Leon, A. C., \& Casey, B. J. (2006). The face behind the mask: A developmental study. Developmental Science, 9, 288-294.

Tottenham, N., Tanaka, J., Leon, A. C., McCarry, T., Nurse, M., Hare, T. A., ... Nelson, C. A. (2009). The NimStim set of facial expressions: Judgments from untrained research participants. Psychiatry Research, 168, 242-249.

Viggiano, M. P., Righi, S., \& Galli, G. (2006). Category-specific visual recognition as affected by aging and expertise. Archives of Gerontology and Geriatrics, 42, 329-338.

Vlamings, P. H. J. M., Goffaux, V., \& Kemner, C. (2009). Is the early modulation of brain activity by fearful facial expressions primarily mediated by coarse low spatial frequency information? Journal of Vision, 9, 1-13.

Vlamings, P. H. J. M., Jonkman, L. M., \& Kemner, C. (2010). An eye for detail: An eventrelated potential study of the rapid processing of fearful facial expressions in children. Child Development, 81, 1304-1319.

Vlamings, P. H. J. M., Jonkman, L. M., van Daalen, E., van der Gaag, R. J., \& Kemner, C. (2010). Basic abnormalities in visual processing affect face processing at an early age in autism spectrum disorder. Biological Psychiatry, 68, 1107-1113.

Williams, M. A., Berberovic, N., \& Mattingley, J. B. (2007). Abnormal FMRI adaptation to unfamiliar faces in a case of developmental prosopamnesia. Current Biology, 17 1259-1264.

Yin, R. K. (1969). Looking at upside-down faces. Journal of Experimental Psychology, 81, $141-145$. 